\title{
PLASTIC SURGERY AND THE TRAUMA PATIENTS
}

\author{
Khundkar $\mathrm{SH}^{1}$, Khondoker $\mathrm{MS}^{2}$, Awwal $\mathrm{R}^{3}$, Hossain $\mathrm{SI}^{4}$, Faruquee SMAI ${ }^{5}$
}

\begin{abstract}
:
A prospective observational study was carried out in the Department of Plastic Surgery, Dhaka Medical College Hospital. 261 patients were included as study population that were referred from Casualty Surgery, Dhaka Medical College Hospital. This population represents 15.94\% of the total trauma patients admitted in Casualty Department as emergency patient during the year 2009. Among them male patients were predominant (65.52\%). On an average nearly 22 patients treated in a month as emergency patients. Most of the patients were between 30+-40 years and 20+-30 years age group. Aetiology of trauma according to history revealed road traffic accident as the cause in highest number of cases about $42.91 \%$ followed by machinery injury $34.86 \% .41 .76 \%$ of the injury managed in hand region which was highest. $34.87 \%$ of the patients were managed by flap cover and $49.42 \%$ patients required skin graft. Other various plastic surgical procedures were done in rest (15.71\%) of the patients. Average hospital stay was 19.34 \pm 5.24 days among the admitted patients. Follow up of the patients showed that majority of the patients had full recovery (about 55.55\%.) .
\end{abstract}

J Dhaka Med Coll. 2009; 18(2) : 144-149

\section{Introduction:}

The word "plastic" in "Plastic Surgery" does not mean "artificial," but is derived from the ancient Greek word "plastikos," which means to mold or give form. Plastic surgery includes both the reconstructive and aesthetic subspecialties. Bangladesh is a developing country with lots of opportunities. Plastic Surgery is booming specialty in our country. Plastic Surgery is part and parcel of trauma care. Approximately $20 \%$ of the casualty patients require plastic surgical procedure ${ }^{1}$. Trauma is one of the main causes of upperand lower-limb defects. Limb injuries frequently result in complex defects, hence reconstruction can be demanding. The majority of hand injuries are caused by industrial or agricultural accidents. About $13.3 \%$ of these injuries result in permanent disabilities. Furthermore, approximately half of all permanent disabilities are hand injuries ${ }^{2}$. Road traffic accidents are the main cause of lower-extremity trauma ${ }^{3}$. Injuries may be multiple. A mangled extremity may require multiple procedures and years to rehabilitate. The management of extensive and complex defects is challenging and may result in amputation or shortening. Plastic surgery deals with limb trauma, hand injuries, penoscrotal injuries, extensive skin loss and degloving injuries. The basic principles of management of a trauma are aggressive debridement with removal of all devitalized tissue, hemostasis, reduction of fracture, administration of antibiotics and definitive procedure at earliest time ${ }^{4}$. Prevention of accidents and implementation of ATLS (advance trauma and life support) can reduce morbidity significantly ${ }^{5}$. Appropriate management of trauma patients at earliest time can decrease disability and improve quality of life. Burn patients are most of the emergency conditions that are to be treated by plastic surgery but as Dhaka Medical College Hospital has separate specialized burn unit these patients are treated there. Plastic Surgery department in Dhaka Medical College Hospital treats mostly the trauma patients that need emergency care and referred from the Department of Casualty Surgery. Management of trauma care is a very specialized job. Integrated approach towards patients by Casualty, Plastic Surgery,

1. Professor and Head Department of Plastic Surgery, Dhaka Medical College and Hospital.

2. Associate professor, Department of Plastic Suegery, Dhaka Medical College and Hospital.

3. Assistant professor, Department of plastic surgery, Dhaka Medical College and Hospital.

4. Assistant Registrar, Department of plastic surgery, Dhaka Medical College and Hospital.

5. Department of plastic surgery, Dhaka Medical College and Hospital.

Correspondence: Prof. Shafquat Hussain Khundkar 
Orthopedics and Physical medicine ensures effective care to trauma patients.

\section{Objectives:}

General:

- To outline pattern of trauma patients managed by Department of Plastic Surgery Dhaka Medical College Hospital.

\section{Specific:}

1. Age and sex distribution of the trauma patients treated in Department of Plastic Surgery, Dhaka Medical College Hospital.

2. Aetiology of the trauma patients

3. Management and outcome of the trauma patients treated by Plastic Surgery.

\section{Materials and Methods:}

A Prospective observational study was carried out in the year 2009 in the Department of Plastic Surgery, Dhaka Medical College Hospital. All patients that were referred to Plastic Surgery department from Casualty Surgery within 24 hours of the admission were included in this study. Information about particulars of the patients, causing history, clinical examination, relevant investigation, management and outcome of treatments were noted in data sheet. All of the information were complied and tabulated in order to obtain statistical and comprehensive results of the study.

\section{Results:}

Total number of patients treated in casualty surgery during the year 2009 from January to December was 1637. Among them 261 patients were included in the study with above mentioned criteria. It shows that about $15.94 \%$ of the total trauma patients needed plastic surgical management. On an average nearly 22 patients was treated in each month. 28 patients were managed in the month of March which was highest and 16 patients in the month of February which was least. Monthly patients distribution is plotted as bar diagram in Fig: 1. Most of the patients were between $30+-40$ years about $25.67 \%$ followed by $20+-30$ years age group about $24.90 \%$. Male patients were predominant about $65.52 \%$ in contrast to

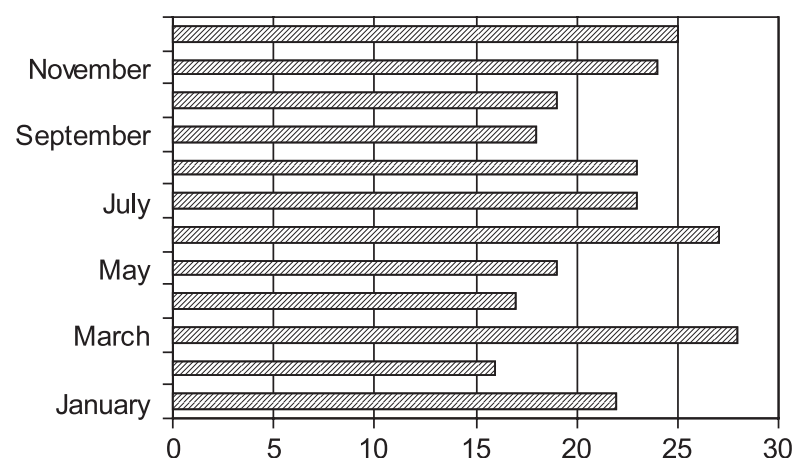

Fig.-1: Bar diagram showing monthly distribution of the patients (n-261)

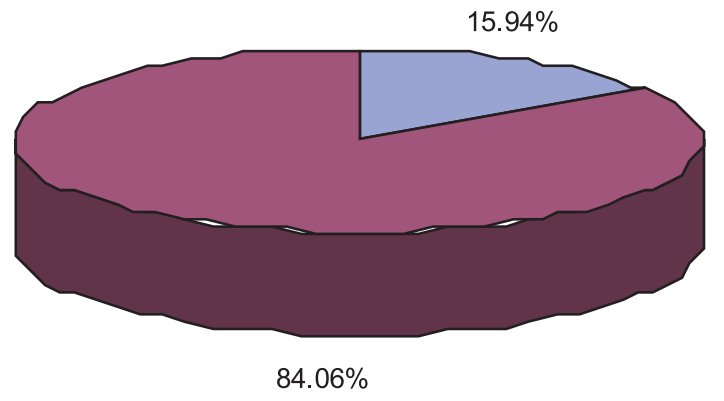

Fig.-2: Pie chart showing percentage of the total patients treated in plastic surgery

the female about $34.48 \%$. Detailed age and sex distribution of the patients are shown in Table: 1. Patient's aetiology of trauma according to history revealed road traffic accident was the highest about $42.91 \%$ followed by machinery injury $34.86 \%$. Other causes were assault about $13.03 \%$, bomb blast $6.90 \%$, dog bite $0.77 \%$ and self inflicted $1.53 \%$. This picture is well documented in tabulated form in Table: 2 . $41.76 \%$ of the injury managed in hand region which was highest followed by upper extremity excluding the hand about $13.41 \%$. Lower extremity (12.26\%) and penoscrotal injury $(11.11 \%)$ were other leading cause of trauma patients treated in plastic surgery department. Detailed injury distribution among the study group are plotted in Table: 3 . Detailed types of wounds and injury picture is presented in Table: 4 and Table:5. Regarding the 
Table-I

Age and Sex distribution of the patients (n-261)

\begin{tabular}{|c|c|c|c|c|}
\hline \multirow[t]{2}{*}{$\overline{\text { Age }}$} & \multicolumn{2}{|c|}{ Sex } & \multirow[t]{2}{*}{ Number of patients } & \multirow[t]{2}{*}{ Percentage } \\
\hline & Male & Female & & \\
\hline $0-10$ years & 17 & 9 & 26 & 9.96 \\
\hline $10+-20$ years & 23 & 11 & 34 & 13.03 \\
\hline $20+-30$ years & 41 & 24 & 65 & 24.90 \\
\hline $30+-40$ years & 45 & 22 & 67 & 25.67 \\
\hline $40+-50$ years & 21 & 13 & 34 & 13.03 \\
\hline $50+$ years and above & 24 & 11 & 35 & 13.41 \\
\hline Total & 171 & 90 & 261 & 100 \\
\hline Percentage & 65.52 & 34.48 & 100 & \\
\hline
\end{tabular}

Table-II Aetiology of injury (n-261)

\begin{tabular}{lcc}
\hline Aetiology of Injury & $\begin{array}{c}\text { Number of } \\
\text { patients }\end{array}$ & Percentage \\
\hline Road traffic accident & 112 & 42.91 \\
Machinery injury & 91 & 34.86 \\
Bomb blast & 18 & 6.90 \\
Self inflicted & 4 & 1.53 \\
Dog bite & 2 & 0.77 \\
Assault & 34 & 13.03 \\
\hline Total & 261 & 100 \\
\hline
\end{tabular}

Table-III Distribution of Trauma (Anatomically) (n-261)

\begin{tabular}{lcc}
\hline $\begin{array}{l}\text { Distribution of } \\
\text { Injury }\end{array}$ & $\begin{array}{c}\text { Number of } \\
\text { patients }\end{array}$ & Percentage \\
\hline Finger & 109 & 41.76 \\
Upper extremity & 35 & 13.41 \\
Lower extremity & 32 & 12.26 \\
Trunk & 21 & 8.05 \\
Facial & 12 & 4.60 \\
Penoscrotal & 29 & 11.11 \\
Multiple & 23 & 8.81 \\
\hline Total & 261 & 100 \\
\hline
\end{tabular}

Table-IV

Types of wounds in patients (n-261)

\begin{tabular}{llcc}
\hline Types of wounds & Number of patients & Percentage \\
\hline Tidy & 26 & 9.96 & \\
Untidy & Bruise & 5 & 1.92 \\
& Puncture/Bite & 7 & 2.68 \\
& Abrasion & 5 & 1.92 \\
& Laceration & 67 & 25.67 \\
& Avulsion & 56 & 21.46 \\
& Crush & 43 & 16.47 \\
Multiple & & 52 & 19.92 \\
\hline Total & 261 & 100 & \\
\hline
\end{tabular}


Table-V

Detailed injury presentation of the patients (n-261)

\begin{tabular}{|c|c|c|c|}
\hline Distribution of Injury & & Number of patients & Percentage \\
\hline \multirow[t]{6}{*}{ Finger $41.76 \%$} & Tendon injury & 23 & 8.81 \\
\hline & Fracture With soft tissue loss & 7 & 2.68 \\
\hline & Exposed bone & 17 & 6.51 \\
\hline & Exposed tendon & 13 & 4.98 \\
\hline & Pulp loss & 27 & 10.35 \\
\hline & Amputation & 22 & 8.35 \\
\hline \multirow[t]{3}{*}{ Upper extremity $13.41 \%$} & Degloving injury & 23 & 8.81 \\
\hline & Exposed bone & 4 & 1.53 \\
\hline & Soft tissue loss & 8 & 3.07 \\
\hline \multirow[t]{4}{*}{ Lower extremity $12.26 \%$} & Degloving injury & 15 & 5.75 \\
\hline & Exposed bone & 7 & 2.68 \\
\hline & Soft tissue loss & 6 & 2.30 \\
\hline & Tendon injury & 4 & 1.53 \\
\hline \multirow[t]{2}{*}{ Trunk 8.05\% } & Avulsion injury & 17 & 6.51 \\
\hline & Soft tissue loss & 4 & 1.53 \\
\hline \multirow[t]{3}{*}{ Facial $4.60 \%$} & Laceration & 6 & 2.30 \\
\hline & Puncture & 2 & 0.77 \\
\hline & Sharp cutting & 4 & 1.53 \\
\hline \multirow[t]{2}{*}{ Penoscrotal $11.11 \%$} & Degloving injury & 27 & 10.35 \\
\hline & Sharp cutting & 2 & 0.77 \\
\hline Multiple & & 23 & 8.81 \\
\hline Total & 261 & 100 & \\
\hline
\end{tabular}

management $49.42 \%$ of the patients were managed by skin graft which was most. Other plastic surgical procedure like various flap cover and replantation done in rest of the patients. Detailed management procedure is shown in Table: 6 and Fig-3. Among 261 patients 142 patients were admitted and transferred under plastic surgery and treated. Other 119 patients were treated as a daycase and treated on the day of referral and follow up

Table-VI

Treatment of the patients (n-261)

\begin{tabular}{llcc}
\hline Treatment & & Number of patients & Percentage \\
\hline Skin Graft & & 129 & 49.42 \\
Primary closure & & 41 & 15.71 \\
Flap Cover & Rotation flap & 6 & 2.30 \\
& Groin flap & 6 & 2.30 \\
& Gastrocnemius flap & 3 & 1.15 \\
& Soleus flap & 2 & 0.77 \\
& Chest flap & 4 & 1.53 \\
\multirow{3}{*}{ Finger } & Cross leg flap & 4 & 1.53 \\
& Cross finger flap & 15 & 5.75 \\
\multirow{2}{*}{ Replantation of penis } & 3 & 1.15 \\
Others & Moberg flap & 25 & 9.58 \\
Total & V-Y advancement & 2 & 0.77 \\
\hline
\end{tabular}


done as an outpatient basis. Average hospital stay was $19.34 \pm 5.24$ days among the admitted patients. Follow up of the patients showed that most of the patients had full recovery about $55.55 \%$ but $37.55 \%$ patients had recovery with some deformity mostly due to their deformity during the injury. $6.13 \%$ patients referred to other department or hospital after management in plastic surgery for further treatment. Outcome of the patients are shown in Table:7.
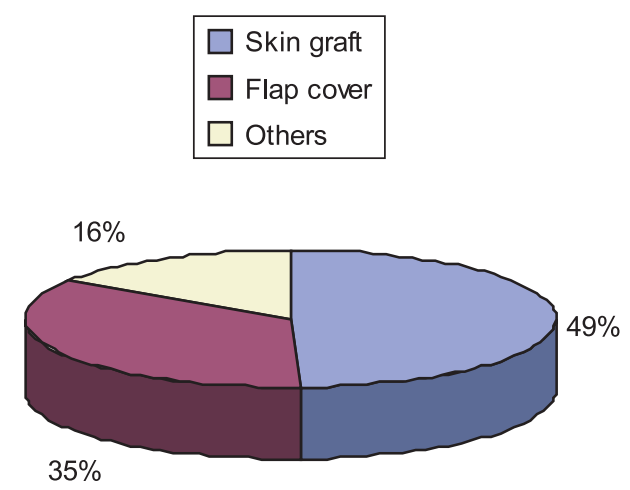

Fig-3: Pie chart showing management of the patients (n-261)

Table-VII

Outcome of patients after treatment (n-261)

\begin{tabular}{|c|c|c|}
\hline $\begin{array}{l}\text { Outcome of } \\
\text { patients }\end{array}$ & $\begin{array}{l}\text { Number of } \\
\text { patients }\end{array}$ & Percentage \\
\hline Complete recovery & 145 & 55.55 \\
\hline $\begin{array}{l}\text { Recovery with some } \\
\text { deformity }\end{array}$ & 98 & 37.55 \\
\hline $\begin{array}{l}\text { Reffered to other } \\
\text { hospital/ Department }\end{array}$ & 16 & 6.13 \\
\hline Death & 2 & 0.77 \\
\hline Total & 261 & 100 \\
\hline
\end{tabular}

\section{Discussion:}

Total of 261 patients were treated in Department of Plastic Surgery, Dhaka Medical College Hospital during the year 2009 as an emergency patients those were referred from Department of Casualty Surgery which is about $15.94 \%$ of the total trauma patients treated in casualty surgery. It should be worth mentioning there is a separate specialized burn unit in Dhaka Medical College Hospital that have 24 hour emergency so a large number of patients with burn are treated there thus obviating the need for treating burn pts in casualty. There is no other study done previously in our country to outline the pattern of trauma patients managed in Plastic Surgery. Moreover there is also very few study to outline the emergency patients treated for trauma and injury. In our study mean age of the patient's was 29.72 \pm SD (21.37) year ranging from 1 month to 68 years. Most of the patients were between $30+-40$ years about $25.67 \%$ followed by $20+-30$ years age group about $24.90 \%$. Male patients were predominant about $65.52 \%$ in contrast with the female about $34.48 \%$ male female ratio was nearly 2:1. Similar study to outline the trauma patients that carried out in $\operatorname{Iran}^{6}, 2009$ reveals patients mean age was 34.7 (standard deviation 19.9) years that is close to our study. The male to female ratio was 3.66 slightly higher numbers of male patients in contrast to our study but it reflects male female sex distribution of the peoples of Iran $^{6}$. Another study carried in Assam, India ${ }^{7}$, 2009 reflects the mean age of emergencies was 28 ( \pm 14 years) similar to our study. A higher prevalence of emergencies was noted among males (55\%) and in the most of the patients was distributed in 19-30 year age group and 31-45 year age group. These results are very similar to our study as we have similar socioeconomic condition and literacy rate in relation to India. Patient's aetiology of trauma according to history revealed road traffic accident was the highest about $42.91 \%$ followed by machinery injury $34.86 \%$. Other causes were assault about $13.03 \%$, bomb blast $6.90 \%$, dog bite $0.77 \%$ and self inflicted $1.53 \%$. In a study in Iran $^{6}$ stated RTA, falls and interpersonal violence were the three most common mechanisms of trauma. In our study fall from height patients were excluded as these patients were usually managed by neurosurgery department but other results are pretty similar. In our study $41.76 \%$ of the injury managed in hand region which was highest followed by upper extremity excluding the hand about $13.41 \%$. Lower extremity (12.26\%) and penoscrotal injury (11.11\%) were other leading cause of trauma patients treated in plastic 
surgery department. In Iran ${ }^{4}$ in contrast to our study $27.6 \%$ patients experienced head injury but these patients were excluded in our study so comparison can not be done. More over hand injury is leading cause of injury in our country but there was only 9.2\% hand injury in Iran $^{6}$ probably due to protective measure taken by people. $49.42 \%$ of the patients were managed by skin graft in Plastic Surgery followed by other various flaps. Procedure like microvascular flap cover or replantation of digits were not done in emergency management as in Dhaka Medical College Hospital there is no such facility and infrastructure though many of the surgeons can perform this procedure with infrastructural support. Most of the patients had full recovery with no deformity $(55.55 \%)$ followed by recovery with some deformity (37.55\%). Deformities were mostly due to type and nature of injury like traumatic amputation of fingers, mangled extremity or self inflicted amputation of penis which could not be managed with highest effort and procedure. Only $0.77 \%$ patients died mostly due to length of time elapsed before the patients arrived in emergency. $6.13 \%$ of the patients were consulted other department for better management.

\section{Conclusion:}

So far the Establishment of the Department of Plastic Surgery, there was no practice for immediate referral and management of trauma victims in Plastic surgery. Trauma patients those who required plastic surgical intervention were usually referred later on. In 2009 considering the interest of the patients both the department of Plastic Surgery and Casualty Surgery agreed to manage the patients with a coordinated effort and patients were referred to Plastic Surgery at ' $O$ ' hour of arrival in the Casualty Surgery. Management of trauma patients with expertise and knowledge at appropriate and earliest time can reduce morbidity and improves quality of life. Total of 261 patients treated in plastic surgery which was $15.94 \%$ of the total trauma patients with male predominance. A large number of trauma patients required Plastic surgical intervention. Road traffic accidents were the leading cause of injury and hand and upper extremity were affected mostly. Average hospital stay of the admitted patients was reduced. Most of the patients had early and satisfactory recovery which reflects early management is the key to reduce morbidity. The limitation of study is that the study period was only 1 year which is short. and the procedure, outcome and follow up of the patients are not elaborated in the study. Further study with longer duration, detailed management may reveal actual picture of trauma patients treated by Plastic Surgery in our country.

\section{Reference:}

1. Khundkar SH, Hossain SI, 2007. Plastic Surgery -Ultimate in Trauma management. Proceedings of the $200710^{\text {th }}$ international surgical congress of society of surgeons of Bangladesh, Dhaka, 710 December 2007, pp 9 , Dhaka: Society of surgeons, Bangladesh..

2. Soucacos PN, Zoubos AB, Korompilias AV, Vekris MD. Versatility of the island forearm flap in the management of extensive skin defects of the hand. Injury 2008; 39(Suppl 3):49-56.

3. Arndt N, Grzebieta RH. Lower extremity injuries in side impact vehicle crashes. Int $\mathrm{J}$ Crashworthiness 2003; 8:495- 512 .

4. Meuller RV, Mathes SJ. Facial trauma: Soft tissue injuries. Philadelphia: Elsevier.2009.

5. Ali J, Adam R, Butler AK, Chang H, Howard M, Gonsalves D et al. Trauma outcome improves following the advanced trauma life support program in a developing country. J Trauma. 1993 Jun;34(6):890-8.

6. Karbakhsh M, Zandi NS, Rouzrokh M, Zarei MR. Injury epidemiology in Kermanshah:the National Trauma Project in Islamic Republic of Iran. Eastern Mediterranean Health Journal 2009; 15(1): 57-68.

7. Saddichha S, Saxena MK, Pandey V, Methuku M. Emergency medical epidemiology in Assam, India. Journal of Emergencies Trauma and Shock 2009; 2(3):170-174. 